\title{
Identification of in vitro-in vivo components of Caoguo using accelerated solvent extraction combined with gas chromatography-mass spectrometry integrated with network pharmacology on indigestion
}

\author{
Shan Shi ${ }^{1 \#}$, Yifan Luo ${ }^{1 \#}$, Yue $\mathrm{Ma}^{1}$, Yanjie $\mathrm{Chu}^{2}$, Yidan Wang ${ }^{1}, \mathrm{Xiahui}^{\mathrm{C}}{ }^{2}{ }^{2}$, Yang $\mathrm{Chu}^{1}$ \\ ${ }^{1}$ Department of Pharmacy, The First Hospital of China Medical University, Shenyang, China; ${ }^{2}$ Department of Pharmaceutical Analysis, School of \\ Pharmacy, Shenyang Pharmaceutical University, Shenyang, China \\ Contributions: (I) Conception and design: Y Chu, X Chen; (II) Administrative support: Y Chu; (III) Provision of study materials or animals: X Chen; (IV) \\ Collection and assembly of data: Y Ma, Y Chen, Y Wang; (V) Data analysis and interpretation: S Shi, Y Luo; (VI) Manuscript writing: All authors; (VII) \\ Final approval of manuscript: All authors. \\ \#These authors contributed equally to this work. \\ Correspondence to: Yang Chu. Department of Pharmacy, The First Hospital of China Medical University, 155 Nanjing North Street, Shenyang \\ 110001, China. Email: chuyang7546@163.com.
}

Background: Caoguo (Tsaoko Fructus), a traditional Chinese medicine, is widely used as medicine and
dietary spices. Volatile components are among its important bioactive constituents used to treatment of
abdominal distension and pain, but the mechanism is not clear up to now. The purpose of this study was
to develop a simple, sensitive, and accurate method to analyze and identify components of Caoguo in vitro
and in vivo, and further investigate the therapeutic mechanism of Caoguo on indigestion using network
pharmacology. Methods: Caoguo were extracted by accelerated solvent extraction (ASE) and n-hexane:ethyl acetate $(1: 1, \mathrm{v} / \mathrm{v})$ was selected as the extraction solvent. Gas chromatography-mass spectrometry (GC-MS) was adopted to analyze and identify the volatile components in vitro and in vivo. Network pharmacology including protein-protein network construction, Gene Ontology (GO) enrichment and pathway enrichment analysis and component-target-pathway network construction was applied.

Results: By comparing the retention times and mass spectrometry data, as well as retrieving the reference literature, a total of 169 components were tentatively identified in Caoguo extract and 43 components were identified in rats plasma samples for the first time. The results of network pharmacology analysis indicated that the potential mechanism was mainly associated with regulation of lipolysis in adipocytes and serotonergic synapse signaling pathway, which might be responsible for the effect of indigestion.

Conclusions: Caoguo was first extracted by ASE and the volatile chemical components in vivo were first identified by GC-MS. Coupled with network pharmacology analysis, a network of component-targetpathway was constructed to reveal the possible mechanism of Caoguo in treatment of indigestion. This study provided a new reference method for the extraction and analysis of Caoguo, laid a chemical basis for in-depth studies on pharmacodynamics and pharmacology, and revealed an updated understanding of the therapeutic effects of Caoguo on indigestion.

Keywords: Traditional Chinese medicine; gas chromatography-mass spectrometry (GC-MS); accelerated solvent extraction (ASE); Caoguo; network pharmacology

Submitted Jun 04, 2021. Accepted for publication Jul 07, 2021.

doi: 10.21037/atm-21-3245

View this article at: https://dx.doi.org/10.21037/atm-21-3245 


\section{Introduction}

Caoguo (Tsaoko Fructus), is the dried and mature fruit of Amomum tsao-ko Crevost et Lemaire, exhibits a broad biological activities such as anti-infectious, anti-oxidant, anti-proliferation and $\alpha$-glucosidase inhibitory activity (1-5). As a herb, Caoguo can used as medicine and dietary spices, which has pharmacological effects including reduce plasma and liver lipids, reduce plasma glucose levels, adjust gastrointestinal metabolic function, anti-inflammatory, analgesic and neuroprotective effects (6-8). Caoguo Zhimu Ddecoction with CaoGuo as the monarch was used in clinical for treatment of epilepsy and chronic renal failure $(9,10)$. Mongolian medicine containing twenty-one Chinese medicines was used in chronic aplastic anemia therapy (11).

Volatile oil is the main components in Caoguo, many methods such as reflux extraction, steam distillation, supercritical fluid $\mathrm{CO}_{2}$ extraction, ultrasonic extraction and microwave extraction have been adopt for volatile oil extraction from Caoguo in recent years (12-16). Different extraction methods and solvents both impact on the components and contents of volatile oil, causing distinct extraction efficiency and yields. Traditional extraction methods such as soaking extraction and ultrasonic extraction are easy to operate, but they are both timeconsuming process and a large amount of medicinal materials and solvents are always required, causing difficult to extract the chemical components that are unstable and easily oxidized. While supercritical fluid $\mathrm{CO}_{2}$ extraction method don't need organic solvents in the whole extraction process and has a higher extraction efficiency for oil, but it is generally suitable for extraction of lipophilicity and small molecular substances and cost much than other extraction methods due to expensive equipment. Accelerated solvent extraction (ASE) technique, as a fast and efficient extraction method with low solvent consumption, has been adopt for active components extraction in many traditional Chinese medicine herbs such as Xanthii Fructus, Salvia miltiorrbiza, Aucklandia lappa Decne $(17,18)$.

The network pharmacology can construct a network model to explain the relationship among the compounds-targetspathways-diseases by combining the system pharmacology and systems biology. As a paradigm, network pharmacology has been used more and more in traditional Chinese medicine research for the purpose to predict the multi-targets of the mechanism of diseases treatment (19-21).

This study is aimed to apply ASE combined gas chromatography-mass spectrometry (GC-MS) method to extract and identify the in vivo and in vitro volatile constituents of Caoguo. Based on the identified components, network pharmacology analysis was proceeded to predict the protein/gene targets and signaling pathways of Caoguo in the treatment of indigestion. We present the following article in accordance with the ARRIVE reporting checklist (available at https://dx.doi.org/10.21037/atm-213245).

\section{Methods}

\section{Reagents and materials}

Dried Caoguo, derived from the Yunnan province (China), was purchased from Beijing Tongrentang of Chinese medicinal material in Shenyang, Liaoning, China. Reference standards (purity >98\%) of $\alpha$-pinene, $\beta$-pinene, eucalyptol, nerolidol, and $\alpha$-terpineo were purchased from SinoStandards (Chengdu, Sichuan, China) for GCMS analysis. Distilled water was provided by Wahaha (Hangzhou, Zhejiang, China). Methanol (chromatographic grade) was purchased from Sigma-Aldrich Company (Shanghai, China). Ethyl acetate and hexane of chromatographic grade were obtained separately from Tianjin Fuyu Chemical Limited Company (Tianjin, China) and Shandong Yuwang Industrial (Yucheng, Shandong, China).

\section{Preparation of Caoguo extract}

The Caoguo samples were extracted by ASE, which was carried out with a Dionex ASE 350 (Thermo Fisher Scientific, Waltham, MA, USA). All extractions were equipped with $34 \mathrm{~mL}$ capacity stainless steel cells. A cellulose filter was placed at the bottom of the extraction cell, and then $5 \mathrm{~g}$ Caoguo powder mixed with a small amount of diatomaceous earth was poured into the extraction cell. Then, the remaining void was filled with diatomaceous earth, with a cellulose filter placed on the top. Mixture solvent of $\mathrm{n}$-hexane:ethyl acetate $(1: 1, \mathrm{v} / \mathrm{v})$ was used as extraction solvent. Three static cycles of each $15 \mathrm{~min}$ under pressure of $1,500 \mathrm{psi}(10.3 \mathrm{MPa})$ and temperature of $110{ }^{\circ} \mathrm{C}$, then the extraction cell was flushed with solvent $(100 \%$ of the cell volume) and purged with nitrogen for $90 \mathrm{~s}$. All the extracts were collected in $250 \mathrm{~mL}$ bottles and filtered.

\section{Animals dosing and sampling}

A total of 12 male pathogen-free Sprague-Dawley (SD) rats weighing 180-220 g were provided by the Experimental 
Animal Center of Shenyang Pharmaceutical University. Rats were housed and bred under a $12 \mathrm{~h}$ dark-light cycle at suitable room temperature $\left(20-25^{\circ} \mathrm{C}\right)$ and humidity (40-70\%). Rats were placed in this conditions for one week with free access to water and standard rodent food before experiment. Experiments were performed under a project license (No.: SYPU-IACUC-C2018-12-26-103) granted by institutional ethics board of Shenyang Pharmaceutical University, in compliance with Shenyang Pharmaceutical University institutional guidelines for the care and use of animals. All the rats were randomly divided into two groups, with six in each group, and fasted overnight prior to the experiments. Caoguo extract was redissolved with $0.5 \%$ carboxymethyl cellulose sodium (CMC-Na) solution and diluted to an appropriate concentration $(0.1 \mathrm{~g} / \mathrm{mL})$. A volume of $10 \mathrm{~mL} / \mathrm{kg}$ (equivalent to raw medicine $100 \mathrm{~g} / \mathrm{kg}$ ) was intragastrically administrated to rats in the treatment group and the same volume of $0.5 \% \mathrm{CMC}-\mathrm{Na}$ was intragastrically administrated to rats in the vehicle group, doses in both groups were once every two hours for a total of three times. After the last dosing, plasma samples $(\sim 0.5 \mathrm{~mL})$ were collected into heparinized tubes from the post-orbital venous plexus at $0.25,0.5,075,1,1.5,2$, and $3 \mathrm{~h}$. Then, the samples were centrifuged with speed of $4,000 \mathrm{rpm}$ for $10 \mathrm{~min}$. The samples were stored at $-80{ }^{\circ} \mathrm{C}$ before analysis.

\section{Sample preparation of Caoguo extract and rats plasma for GC-MS analysis}

The Caoguo extract processed by ASE was dissolved in an appropriate amount of $\mathrm{n}$-hexane/ethyl acetate $(1: 1, \mathrm{v} / \mathrm{v})$ and vortex-mixing for $5 \mathrm{~min}$, after stand still for $3 \mathrm{~min}$ and then was centrifuged at 4,000 rpm for $10 \mathrm{~min}$. The supernatant was transferred to sampler vials and an aliquot of $1 \mu \mathrm{L}$ was injected into the GC-MS system for analysis.

Plasma samples of $200 \mu \mathrm{L}$ were mixed with $200 \mu \mathrm{L}$ $\mathrm{n}$-hexane, vortexed for $5 \mathrm{~min}$ and then rested for $5 \mathrm{~min}$. Then, the samples were centrifuged at 4,000 rpm for $10 \mathrm{~min}$. The supernatant was transferred to sampler vials and an aliquot of $1 \mu \mathrm{L}$ of the organic extracts supernatant was injected into the GC-MS system for analysis.

\section{GC-MS conditions and compound identification}

The volatile compounds were analyzed using a GC-MS system, comprising a Trace 1300 GC system combined with a Triplus RSH autosampler, an ISQ MS system, and $\mathrm{X}$ calibur software for data analysis (all components manufactured by Thermo Fisher). Separation was accomplished on a TS-5MS column $(30 \mathrm{~m} \times 0.25 \mathrm{~mm}$, $0.25 \mu \mathrm{m}$; Thermo Fisher). Helium was used as carrier gas at a flow rate of $1.0 \mathrm{~mL} / \mathrm{min}$, and split injection was used with a ratio of 10:1. Temperature programming conditions for qualitative analysis were as follows: the initial oven temperature was set at $40{ }^{\circ} \mathrm{C}$ for $3 \mathrm{~min}$, increased to $130{ }^{\circ} \mathrm{C}$ by increments of $10^{\circ} \mathrm{C} / \mathrm{min}$ keeping for $5 \mathrm{~min}$, finally increased to $280{ }^{\circ} \mathrm{C}$ at a rate of $6{ }^{\circ} \mathrm{C} / \mathrm{min}$ and retained for $15 \mathrm{~min}$. The inlet temperature was set at $280^{\circ} \mathrm{C}$. Electron ionisation mode (EI) with ionization energy at $70 \mathrm{eV}$ was used for mass analysis operating in full scan mode ( $\mathrm{m} / \mathrm{z} 60-500)$.

The chemical components were identified by comparing to the reference spectra from the National Institute of Standards and Technology (NIST) library combined with literature, reference standards and manual analysis. Information of volatile chemical components in Caoguo was also searched from the literature and collected to conduct an Excel database for compound identification and comparison.

\section{Active components screening and target genes prediction}

The chemical compounds were obtained from the traditional Chinese medicine systems pharmacology database (TCMSP) database (http://tcmspw.com/) coupled with identification in this study. Then bioactive compounds with oral bioavailability $(\mathrm{OB}) \geq 30 \%$ and drug-likeness (DL) $\geq 0.18$ were selected for further study. The targets of the bioactive components above were collected from the TCMSP database.

\section{Target genes for indigestion}

Indigestion-related target proteins were collected from the biological targets related to indigestion which were selected from the GeneCards (https://www.genecards.org/) database and then put them into UniProt databases (http://www.uniprot.org/) to search the reviewed target genes of human species

\section{Protein-protein interaction (PPI) network}

The acquired intersection target genes were submitted to the Search Tool for the Retrieval of Interacting Genes/ Proteins (http://string-db.org/) with the organism set to "homo sapiens", the PPIs with the confidence score of $>0.4$ were reserved and then ranked in network by Analyze 


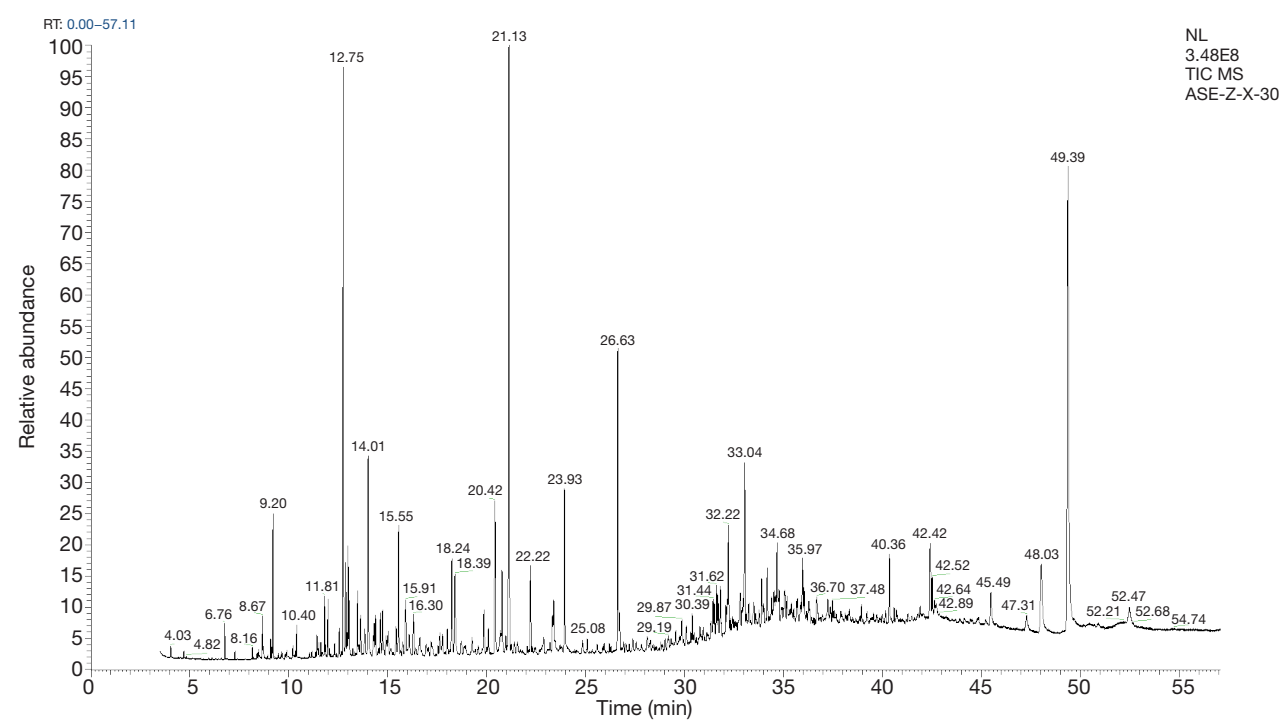

Figure 1 The GC-MS chromatogram of Caoguo extract processed by ASE. GC-MS, gas chromatography-mass spectroscopy; ASE, accelerated solvent extraction.

Network tool in Cytoscape. Furthermore, a PPI network of closely related proteins was made by using the network visualization software Cytoscape (http://cytoscape.org/).

\section{Gene Ontology (GO) enrichment and Kyoto Encyclopedia of Genes and Genomes (KEGG) patbway enrichment analysis and the compound-target-pathway network construction}

The GO enrichment analysis and KEGG pathway enrichment analysis were proceeded. The species were set to "homo sapiens" to predict the potential biological mechanisms in biological process, cell component, molecular function and illustrate the target genes expressed in the pathways.

The network composed of the bioactive compounds, target genes and enriched pathways were constructed by importing data into Cytoscape software.

\section{Results}

\section{Volatile components identification in vitro and in vivo}

The typical total ion chromatogram of the Caoguo extract is shown in Figure 1. All the main components were completely separated within $57 \mathrm{~min}$. The identification results of the GC-MS analysis of Caoguo extract including compound names, molecular weight, molecular formula, retention time and content are presented in Table 1. A total of 169 components were identified in Caoguo extract processed by ASE. Their relative contents were calculated by peak area normalization method. The compounds in Caoguo extract were classified into 18 categories. The prevailing compounds found in Caoguo extract were 39 alcohols (37.1\%), 21 aldehydes (11.71\%), 5 sterols (10.37\%), 21 esters (10.27\%), 19 ketones (6.21\%), 11 alkanes $(4.56 \%), 16$ organic acids $(4.27 \%), 3$ terpenes (3.23\%), 6 alkylene oxides (3.20\%) and 11 olefins (3.01\%).

The total ion chromatograms of Caoguo extract in rat plasma is depicted in Figure 2. The results of GCMS analysis of the volatile components of Caoguo extract processed by ASE in rat plasma is shown in Table 2. Comparing to the plasma sampled from the vehicle group, 43 constituents were identified in rats plasma after dosing Caoguo extract. Among the 43 components, the prevailing compounds were attributed to 15 alkanes (30.37\%), 6 esters (20.13\%), 4 olefins (15.37\%), 5 alcohols (6.57\%) and 6 organic acids $(3.52 \%)$. The following five compounds including bis(6-methylheptyl) benzene-1,2-dicarboxylate (13.72\%), cholesta-3,5-diene (8.61\%), 11-decyltetracosane (5.12\%), 11-pentan-3-ylhenicosane (4.88\%) and methyl (E)-octadec-6-enoate $(3.85 \%)$ were higher in the plasma.

Among the chemical components, $\beta$-pinene, nonanal, eucalyptol, ethyl iso-allocholate, oleic acid, hexadec-9-enoic acid, (5Z,8Z,11Z,14Z,17Z)-icosa-5,8,11,14,17-pentaenoic acid, (8Z,11Z,14Z)-Icosa-8,11,14-trienoic acid and bis(6methylheptyl) benzene-1,2-dicarboxylate were identified 
Table 1 The identified compounds of Caoguo processed by ASE

\begin{tabular}{|c|c|c|c|c|c|}
\hline No. & $\begin{array}{l}\text { Retention } \\
\text { time (min) }\end{array}$ & Compound name & $\begin{array}{l}\text { Molecular } \\
\text { formula }\end{array}$ & $\begin{array}{c}\text { Molecular } \\
\text { weight }\end{array}$ & Content (\%) \\
\hline 1 & 4.53 & 2-Methyl-2-propan-2-yloxirane & $\mathrm{C}_{6} \mathrm{H}_{12} \mathrm{O}$ & 100.09 & 0.03 \\
\hline 2 & 4.65 & Hexan-3-ol & $\mathrm{C}_{6} \mathrm{H}_{14} \mathrm{O}$ & 102.10 & 0.01 \\
\hline 3 & 4.71 & Hexanal & $\mathrm{C}_{6} \mathrm{H}_{12} \mathrm{O}$ & 100.09 & 0.15 \\
\hline 5 & 6.48 & 13-Heptadecyn-1-ol & $\mathrm{C}_{17} \mathrm{H}_{32} \mathrm{O}$ & 252.25 & 0.08 \\
\hline 6 & 6.59 & 2-Butylfuran & $\mathrm{C}_{8} \mathrm{H}_{12} \mathrm{O}$ & 124.09 & 0.02 \\
\hline 7 & 6.77 & Heptanal & $\mathrm{C}_{7} \mathrm{H}_{14} \mathrm{O}$ & 114.10 & 0.77 \\
\hline 8 & 8.26 & 3-Methylpentanoic acid & $\mathrm{C}_{6} \mathrm{H}_{12} \mathrm{O}_{2}$ & 116.08 & 0.02 \\
\hline 12 & 8.67 & Octanal & $\mathrm{C}_{8} \mathrm{H}_{16} \mathrm{O}$ & 128.12 & 0.55 \\
\hline 13 & 8.94 & $\beta$-Pinene & $\mathrm{C}_{10} \mathrm{H}_{16}$ & 136.13 & 1.44 \\
\hline 14 & 9.08 & 1-Methyl-2-propan-2-ylbenzene & $\mathrm{C}_{10} \mathrm{H}_{14}$ & 134.11 & 0.20 \\
\hline 15 & 9.20 & Eucalyptol & $\mathrm{C}_{10} \mathrm{H}_{18} \mathrm{O}$ & 154.14 & 3.81 \\
\hline 16 & 9.30 & (3Z)-3,7-Dimethylocta-1,3,6-triene & $\mathrm{C}_{10} \mathrm{H}_{16}$ & 136.13 & 0.01 \\
\hline 17 & 9.48 & Z,Z,Z-1,4,6,9-Nonadecatetraene & $\mathrm{C}_{19} \mathrm{H}_{32}$ & 260.25 & 0.04 \\
\hline 18 & 9.57 & 1,1-Dimethyl-2-(2-methylbut-3-en-2-yl)cyclopropane & $\mathrm{C}_{10} \mathrm{H}_{18}$ & 138.14 & 0.02 \\
\hline 19 & 9.63 & (E)-Oct-2-enal & $\mathrm{C}_{8} \mathrm{H}_{14} \mathrm{O}$ & 126.10 & 0.05 \\
\hline 25 & 10.40 & Nonanal & $\mathrm{C}_{9} \mathrm{H}_{18} \mathrm{O}$ & 142.14 & 0.61 \\
\hline 26 & 10.48 & (Z)-Icos-11-enoic acid & $\mathrm{C}_{20} \mathrm{H}_{38} \mathrm{O}_{2}$ & 310.29 & 0.08 \\
\hline 27 & 11.17 & 2,7,7-Trimethyl-3-oxatricyclo[4.1.1.02,4]octane & $\mathrm{C}_{10} \mathrm{H}_{16} \mathrm{O}$ & 152.12 & 0.15 \\
\hline 28 & 11.36 & $(8 Z, 11 Z, 14 Z)$-icosa-8,11,14-trienoic acid & $\mathrm{C}_{20} \mathrm{H}_{34} \mathrm{O}_{2}$ & 306.26 & 0.07 \\
\hline 29 & 11.44 & Oleic Acid & $\mathrm{C}_{18} \mathrm{H}_{34} \mathrm{O}_{2}$ & 282.26 & 0.37 \\
\hline 30 & 11.52 & 1,3-Dimethylcyclohexene & $\mathrm{C}_{8} \mathrm{H}_{14}$ & 110.11 & 0.17 \\
\hline 31 & 11.62 & 4,7,7-Trimethylbicyclo[4.1.0]hept-4-en-3-ol & $\mathrm{C}_{10} \mathrm{H}_{16} \mathrm{O}$ & 152.12 & 0.22 \\
\hline 32 & 11.69 & 2-Pentadec-12-ynoxyoxane & $\mathrm{C}_{20} \mathrm{H}_{36} \mathrm{O}_{2}$ & 308.27 & 0.10 \\
\hline 33 & 11.81 & $\alpha$-Terpineol & $\mathrm{C}_{10} \mathrm{H}_{18} \mathrm{O}$ & 154.14 & 3.27 \\
\hline 34 & 11.91 & Benzene-1,2-diol & $\mathrm{C}_{6} \mathrm{H}_{6} \mathrm{O}_{2}$ & 110.04 & 0.11 \\
\hline 35 & 11.98 & [(1S,3S,5S)-4-Methylidene-1-propan-2-yl-3-bicyclo[3.1.0]hexanyl] acetate & $\mathrm{C}_{10} \mathrm{H}_{16} \mathrm{O}$ & 152.12 & 0.63 \\
\hline 36 & 12.12 & 2-Methylheptan-2-ol & $\mathrm{C}_{8} \mathrm{H}_{18} \mathrm{O}$ & 130.14 & 0.06 \\
\hline
\end{tabular}

Table 1 (continued) 
Table 1 (continued)

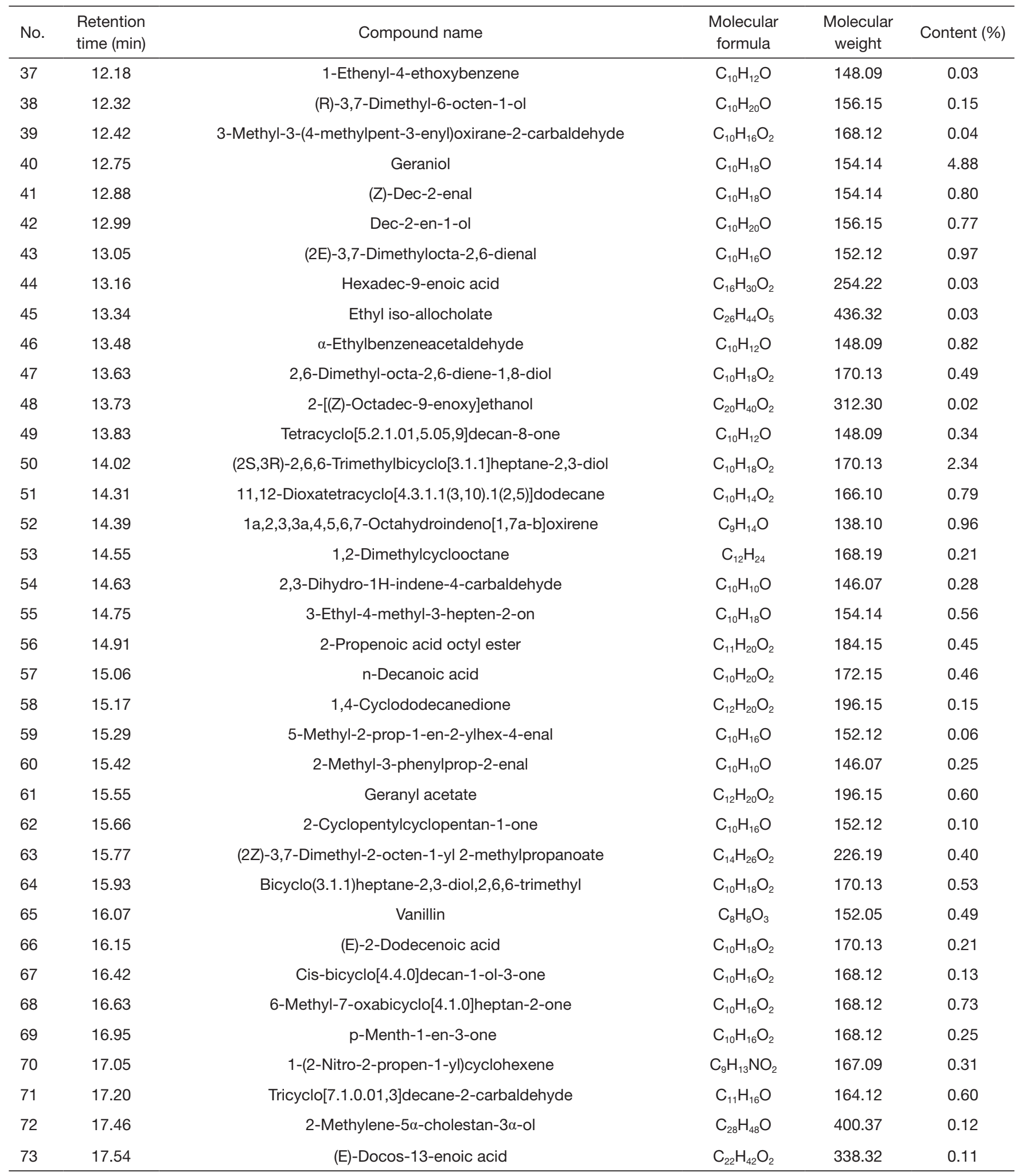

Table 1 (continued) 
Table 1 (continued)

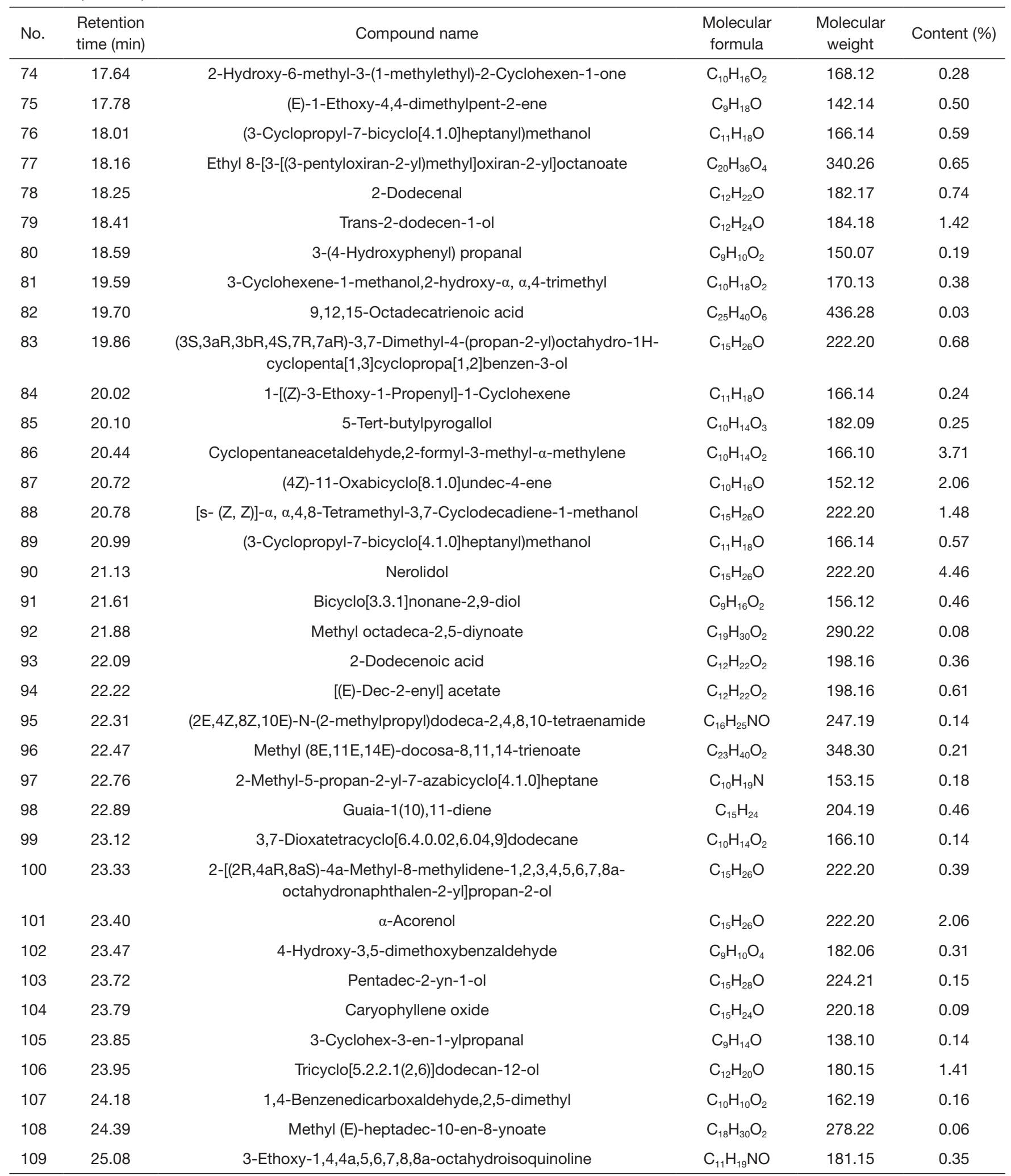

Table 1 (continued) 
Table 1 (continued)

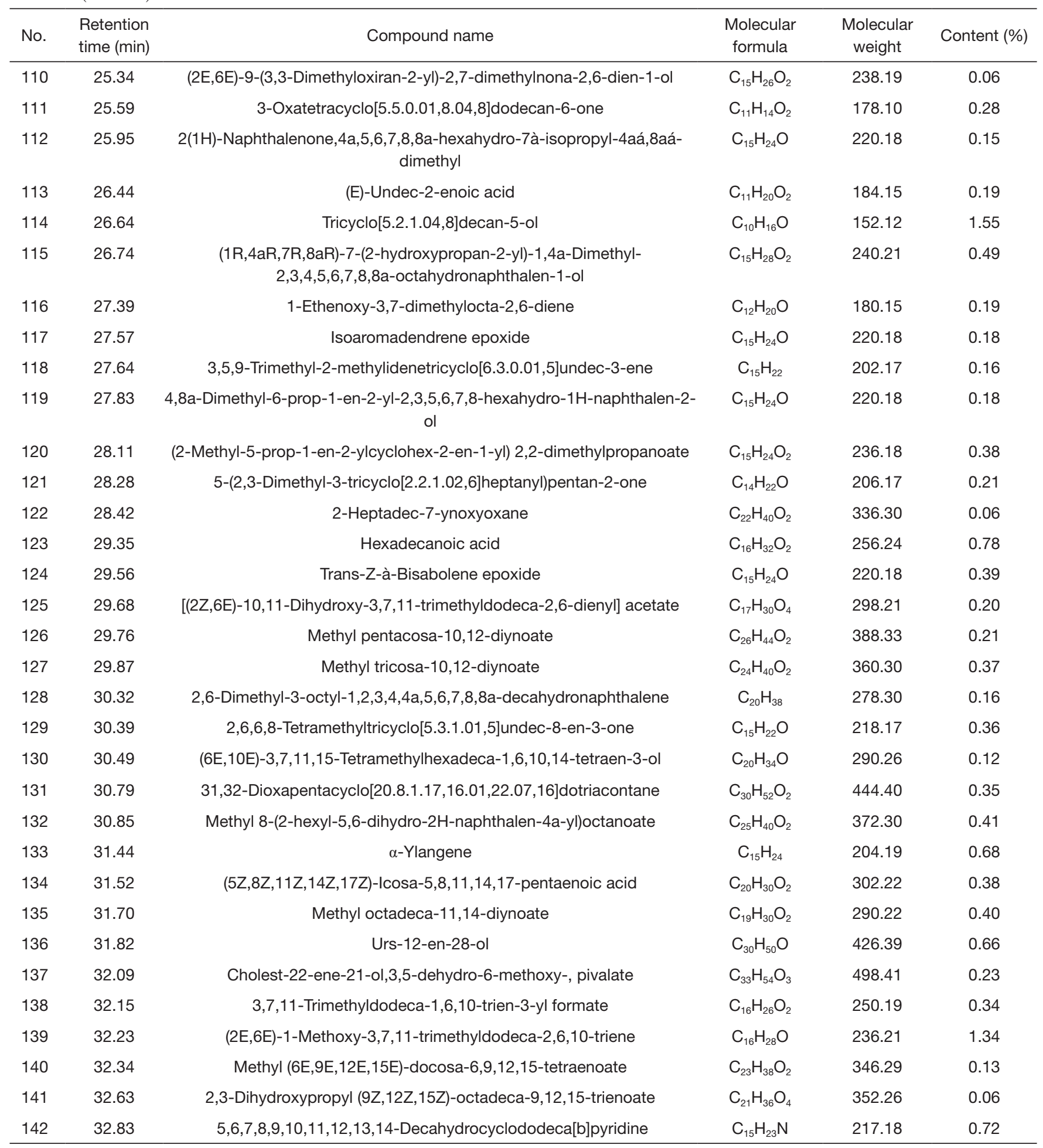

Table 1 (continued) 
Table 1 (continued)

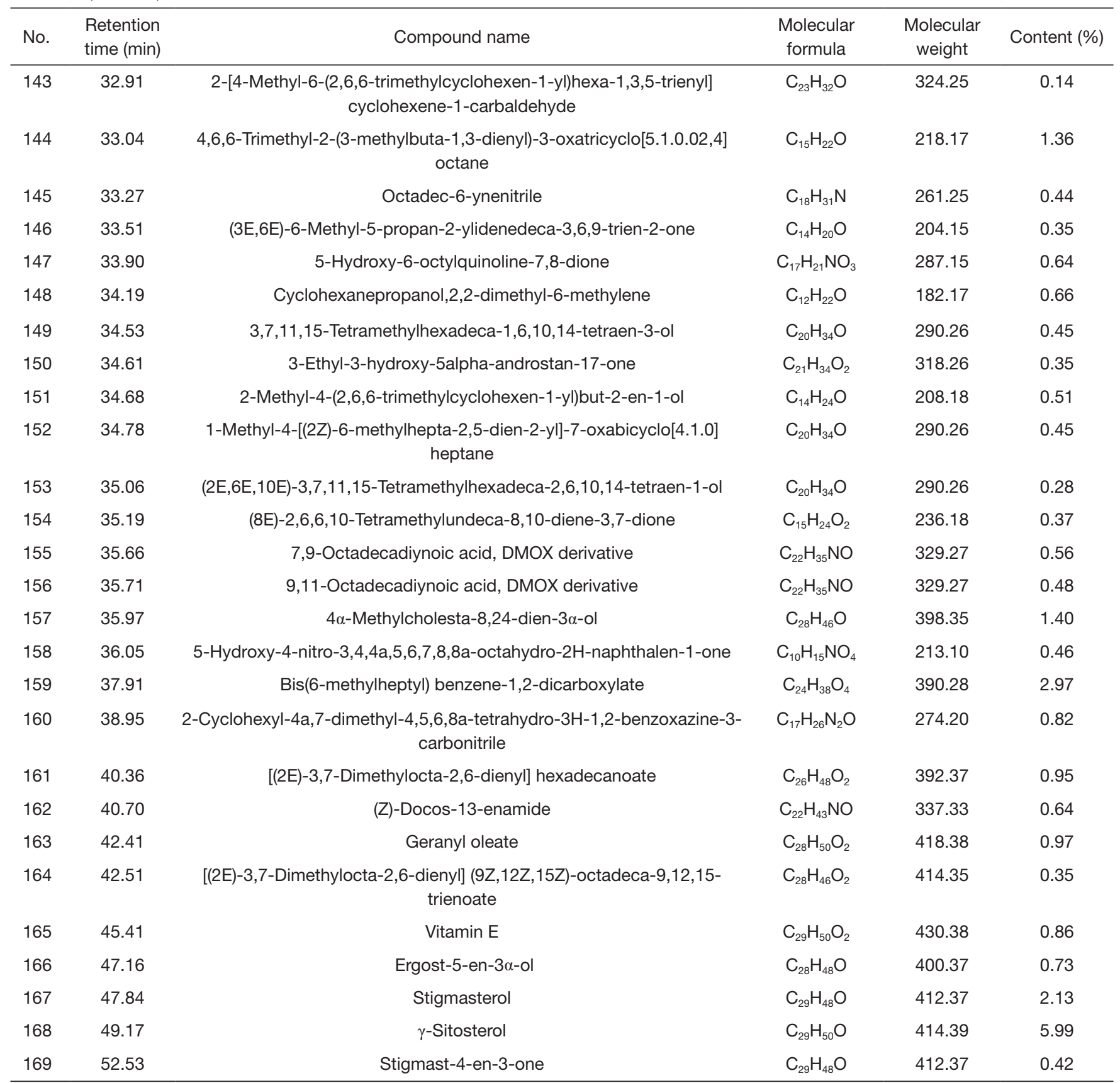

ASE, accelerated solvent extraction.

both in Caoguo extract and rat plasma samples.

\section{Network pharmacology analysis}

According to the screen criteria, twelve active components with 52 target genes in Caoguo were filtered out in the subsequent analysis (Table 3).

There are 19 identified target genes focused on bioactive compounds and indigestion including ESR1, PTGS2, ADRB1, PLAU, PGR, RXRA, PTGS1, SLC6A4, PPARG, MAPK14, DPP4, SCN5A, F10, ADRB2, NR3C2, PIK3CG, HTR2A, LTA4H, OPRD1 by intersection (Table 4). 
The PPI network is showed in Figure 3 contained 17 nodes and twenty-six edges, shows the interaction of PTGS2, PPARG, MAPK14, PGR, SLC6A4, ADRB2, ESR1, PLAU, PTGS1, ADRB1, OPRD1, LTA4H, DPP4, HTR2A, PIK3CG, NR3C2, RXRA ranked according to degree that indicates the importance for treatment of indigestion by Caoguo.

Figure 4 showed the results of GO enrichment analysis of the target genes in biological processes, cell components and molecular functions. The enriched biological processes were dominated by steroid hormone mediated signaling pathway (GO:0043401) and transcription initiation from RNA polymerase II promoter (GO:0006367). Cell components terms mainly contained plasma membrane(GO:0005886). In terms of GO molecular functions, steroid hormone receptor activity (GO:0003707) and enzyme binding (GO:0019899) were mainly enriched.

According to the KEGG enrichment analysis, there were 17 signal pathways enriched and analyzed (Figure 5). Based on the results of KEGG, signal pathway of regulation of lipolysis (hsa04923) and serotonergic synapse (hsa04726) played the important role in treatment of indigestion among the enriched pathways which were displayed in Figures 6 and 7 . The component-target-pathway network was constructed with 12 active components, 52 target genes and 17 pathways (Figure 8), revealed the probable mechanism of Caoguo in treatment of indigestion which were related to multiple active compounds, target genes and pathways.

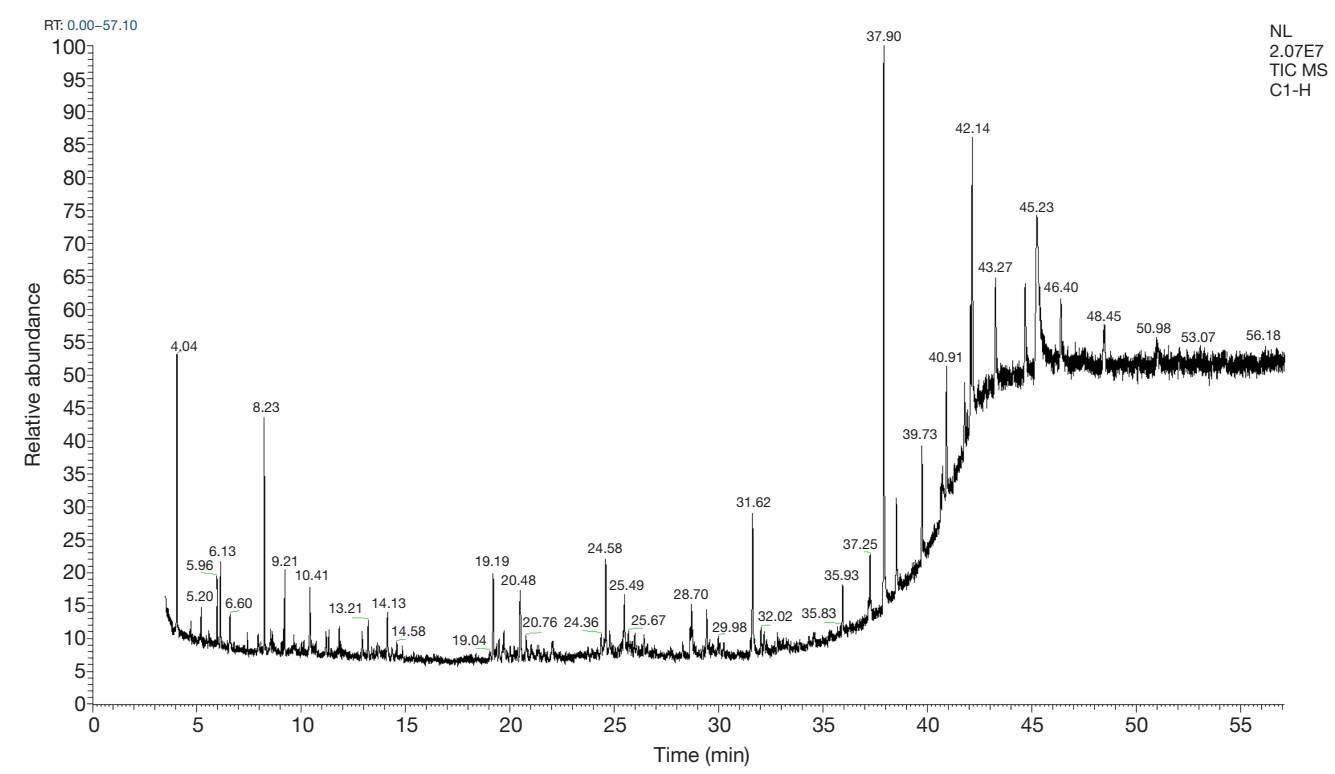

Figure 2 The total ion chromatograms of Caoguo processed by ASE in rats plasma. ASE, accelerated solvent extraction.

Table 2 The identified compounds of Caoguo processed by ASE in rats plasma

\begin{tabular}{|c|c|c|c|c|c|}
\hline No. & $\begin{array}{l}\text { Retention } \\
\text { time (min) }\end{array}$ & Compound name & $\begin{array}{l}\text { Molecular } \\
\text { formula }\end{array}$ & $\begin{array}{c}\text { Molecular } \\
\text { weight }\end{array}$ & Content (\%) \\
\hline 1 & 4.04 & Cyclohepta-1,3,5-triene & $\mathrm{C}_{7} \mathrm{H}_{8}$ & 92.06 & 3.25 \\
\hline 3 & 6.46 & (Z)-Octadec-9-enal & $\mathrm{C}_{18} \mathrm{H}_{34} \mathrm{O}$ & 266.26 & 3.08 \\
\hline 4 & 7.42 & (5Z,8Z,11Z,14Z,17Z)-Icosa-5,8,11,14,17-pentaenoic acid & $\mathrm{C}_{20} \mathrm{H}_{30} \mathrm{O}_{2}$ & 302.22 & 0.10 \\
\hline 6 & 9.21 & Eucalyptol & $\mathrm{C}_{10} \mathrm{H}_{18} \mathrm{O}$ & 154.14 & 1.43 \\
\hline
\end{tabular}

Table 2 (continued) 
Table 2 (continued)

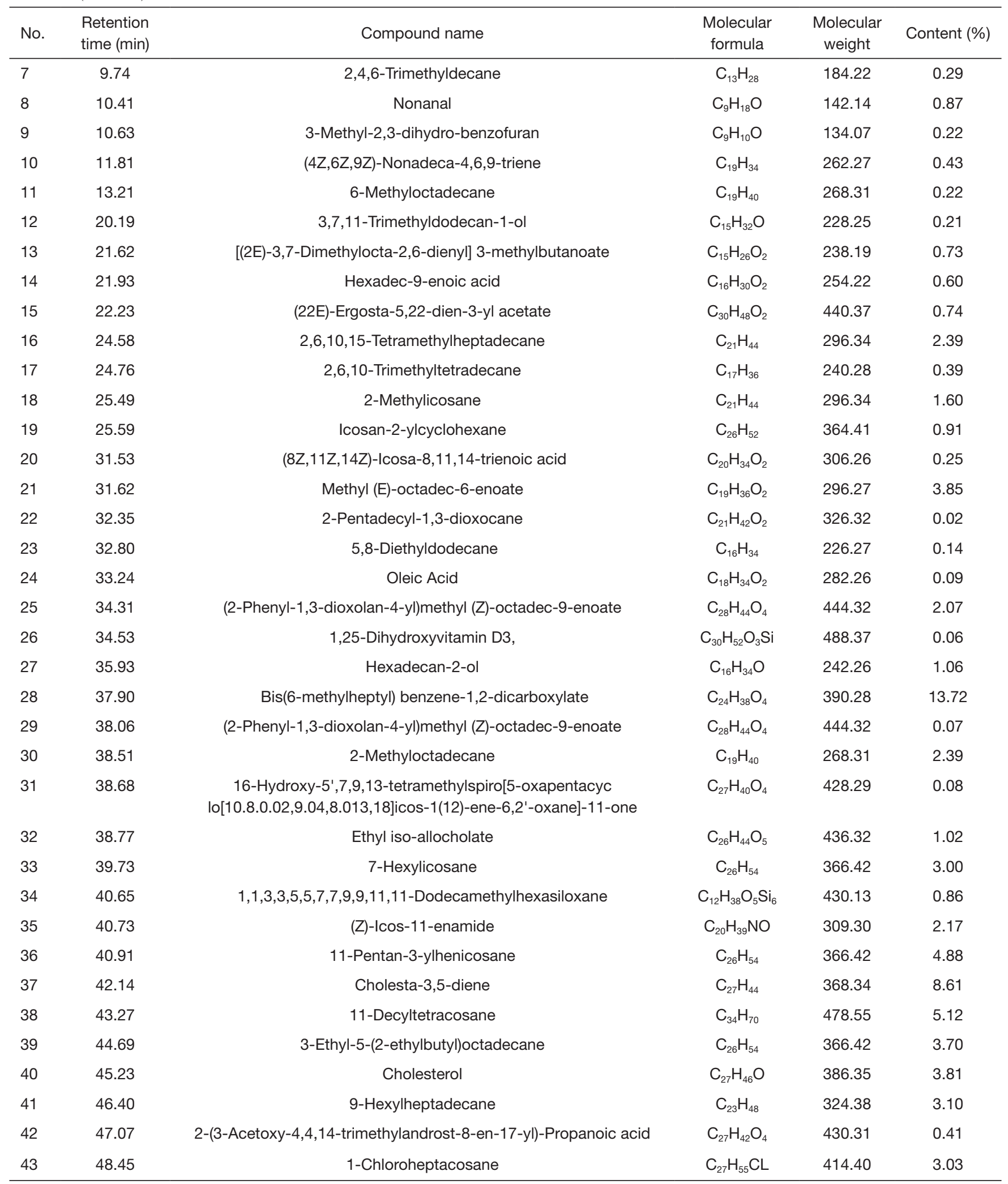

ASE, accelerated solvent extraction. 
Table 3 Twelve active compounds in Caoguo were retrieved from databases and previous experiments

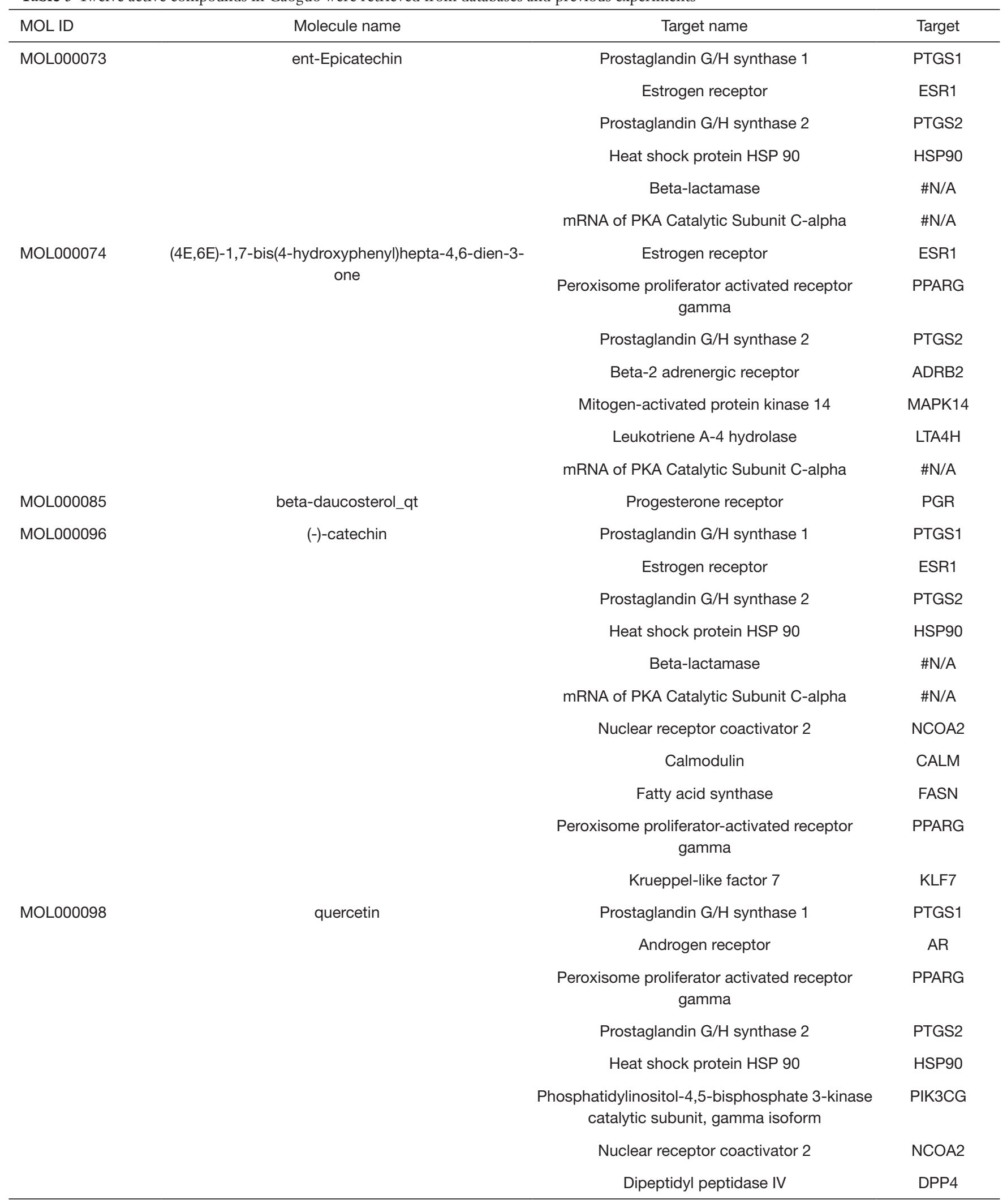

Table 3 (continued) 
Table 3 (continued)

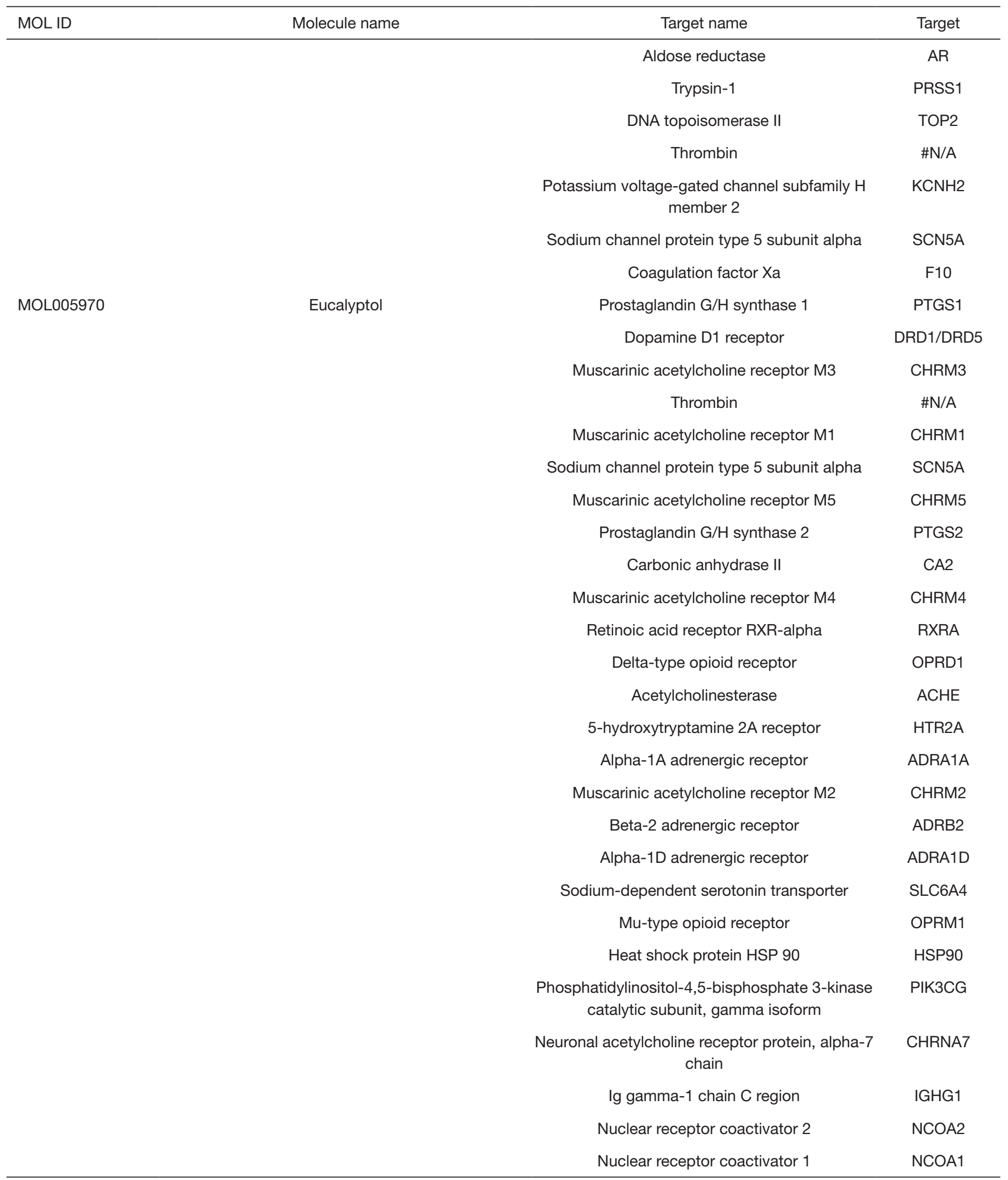

Table 3 (continued) 
Table 3 (continued)

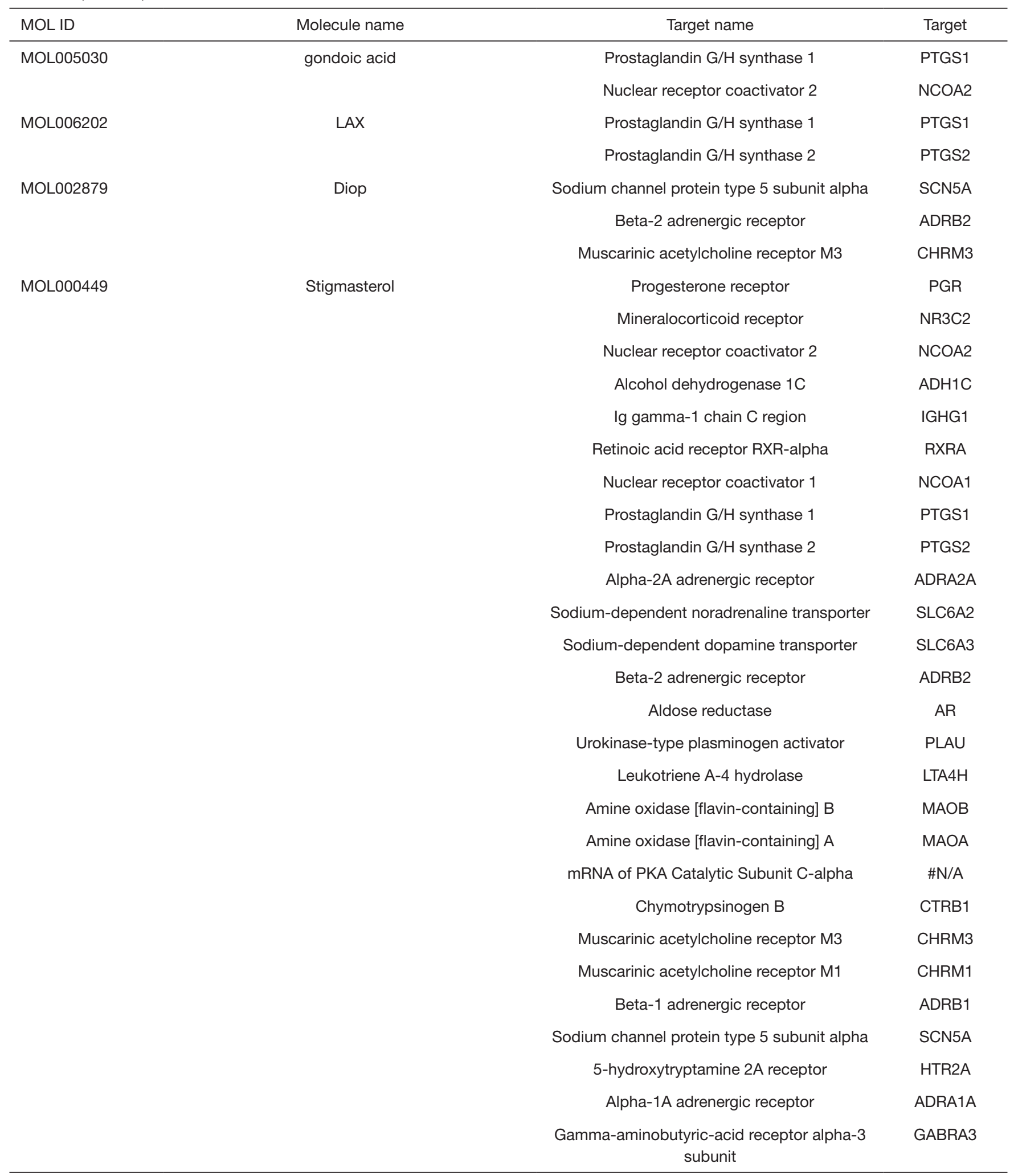

Table 3 (continued) 
Table 3 (continued)

\begin{tabular}{|c|c|c|c|}
\hline MOL ID & Molecule name & Target name & Target \\
\hline & & Alpha-1B adrenergic receptor & ADRA1B \\
\hline & & $\begin{array}{l}\text { Gamma-aminobutyric acid receptor subunit } \\
\text { alpha-1 }\end{array}$ & GABRA1 \\
\hline \multirow[t]{2}{*}{ MOL002320 } & $\gamma$-sitosterol & Progesterone receptor & PGR \\
\hline & & Nuclear receptor coactivator 2 & NCOA2 \\
\hline MOL001507 & stigmast-4-en-3-one & Progesterone receptor & PGR \\
\hline
\end{tabular}

Table 4 Nineteen potential targets of Caoguo related to indigestion

\begin{tabular}{|c|c|}
\hline Target & Protein name \\
\hline ADRB2 & Beta-2 adrenergic receptor \\
\hline DPP4 & Dipeptidyl peptidase IV \\
\hline ESR1 & Estrogen receptor \\
\hline HTR2A & 5-hydroxytryptamine $2 \mathrm{~A}$ receptor \\
\hline LTA4H & Leukotriene A-4 hydrolase \\
\hline MAPK14 & Mitogen-activated protein kinase 14 \\
\hline NR3C2 & Mineralocorticoid receptor \\
\hline PIK3CG & Phosphatidylinositol-4,5-bisphosphate 3-kinase catalytic subunit, gamma isoform \\
\hline PLAU & Urokinase-type plasminogen activator \\
\hline PPARG & Peroxisome proliferator activated receptor gamma \\
\hline PTGS1 & Prostaglandin G/H synthase 1 \\
\hline PTGS2 & Prostaglandin G/H synthase 2 \\
\hline RXRA & Retinoic acid receptor RXR-alpha \\
\hline SCN5A & Sodium channel protein type 5 subunit alpha \\
\hline SLC6A4 & Sodium-dependent serotonin transporter \\
\hline
\end{tabular}




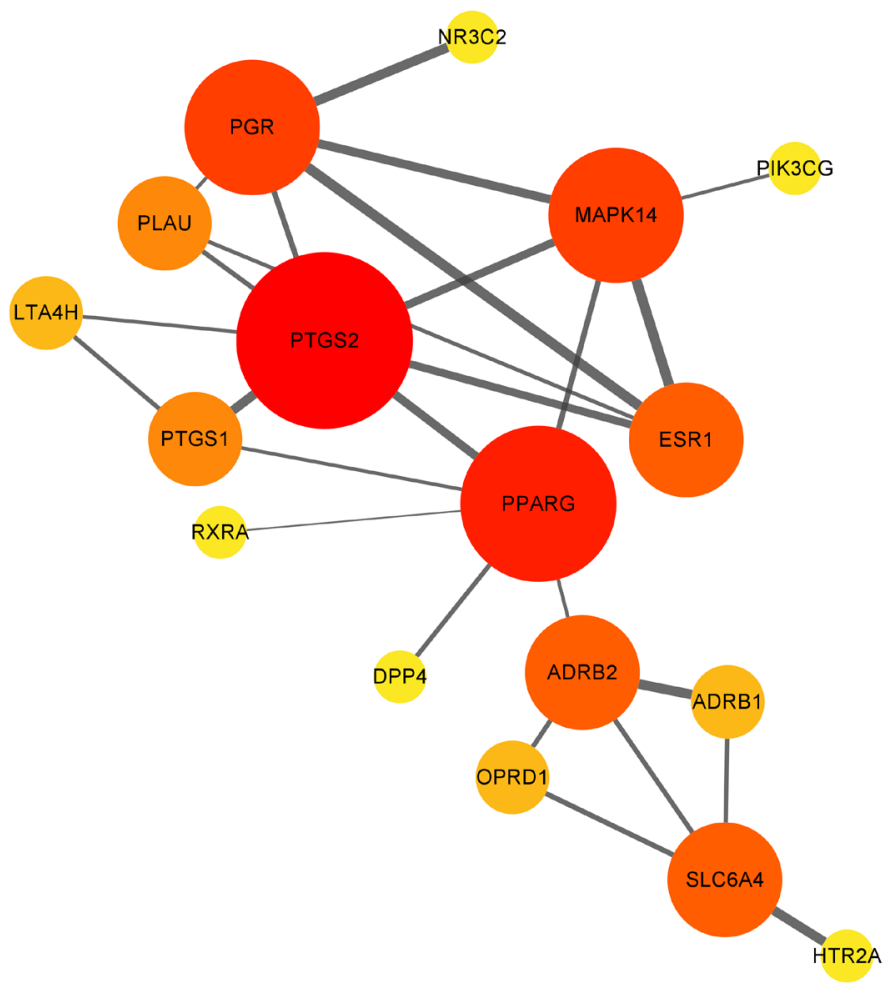

Figure 3 A PPI network (the size and colour indicate the importance of the target genes proportional to their degree and edges represent associations between protein and protein). PPI, protein-protein interaction.

\section{Discussion}

Accelerated solvent extraction (ASE) is a new extraction method which uses organic solvents at high pressure and temperature above boiling point. The ASE procedure was introduced by Dionex (Sunnyvale, CA, USA) in recent years. It uses organic solvents to extract solid and semisolid samples at higher temperatures $\left(50-200{ }^{\circ} \mathrm{C}\right)$ and pressure (10.3-20.6 $\mathrm{MPa}$ ) than those used in traditional solvent extraction procedures (22). High temperature can increase the solubility of the target components in the solvent and reduce solvent viscosity, which is beneficial to the diffusion of solvent molecules into the matrix and increases the dissolution rate of them (23). The high pressure can increase the boiling point of the solvent to above normal boiling point and keep the solvent in a liquid state at this elevated temperature (24). Compared with the traditional extraction method, ASE can significantly improve the extraction rate, shorten analysis time, and reduce environmental pollution. Additionally, as one of the best methods for sample preparation, ASE can reduce or even eliminate errors caused by individual differences in manual operation and increase the sensitivity, accuracy, and reproducibility of analytical tests. In this study, Caoguo was first extracted by ASE which was able to extract a plenitude of potential chemical constituents than other methods reported before $(16,25)$.

Gas chromatography-mass spectroscopy (GC-MS) is one of the most versatile and widely applied technology in modern volatile constituents identification (26) due to its inherent advantages of high resolution (27), rapid separation, low cost, and easy linkage with sensitive and selective detectors (28). Mass spectrometry is a better technique which affords rather complete structural information (29), and it is suitable for the analysis of complex mixtures (30). Some methods based on GC or GC-MS have been reported to detect volatile components in Caoguo (31), but there is still no published data on the in vitro-in vivo components analysis. This is the first time using the GC-MS to identify the components of Caoguo in vivo. 
A

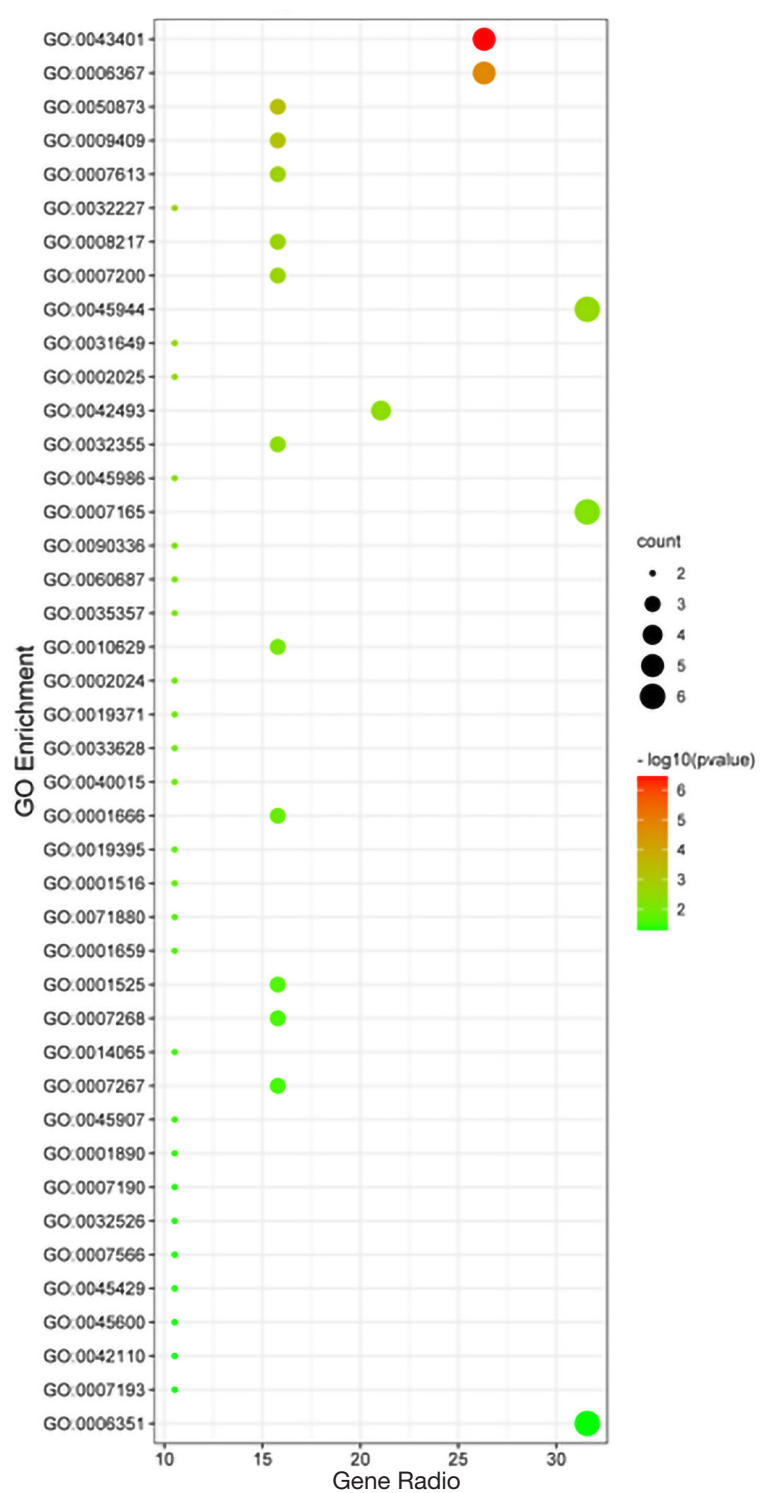

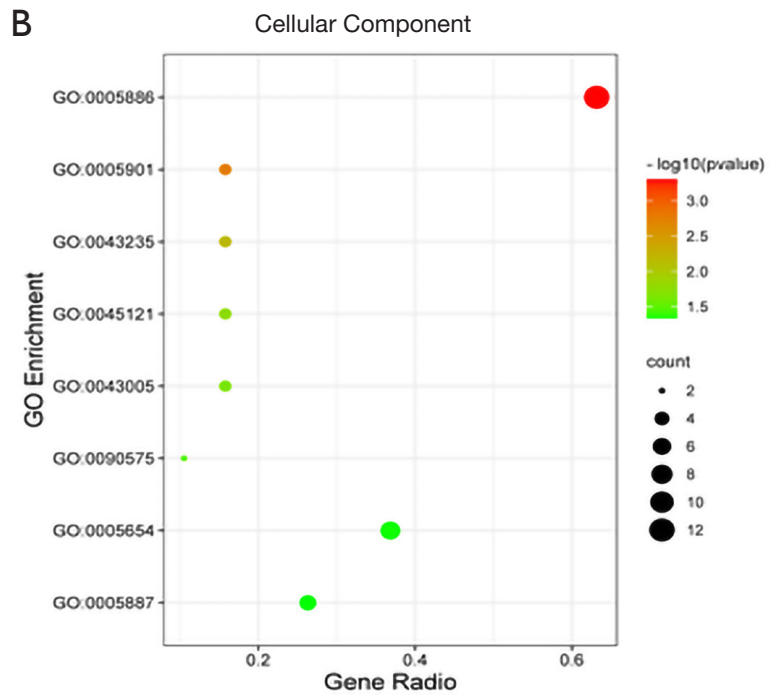

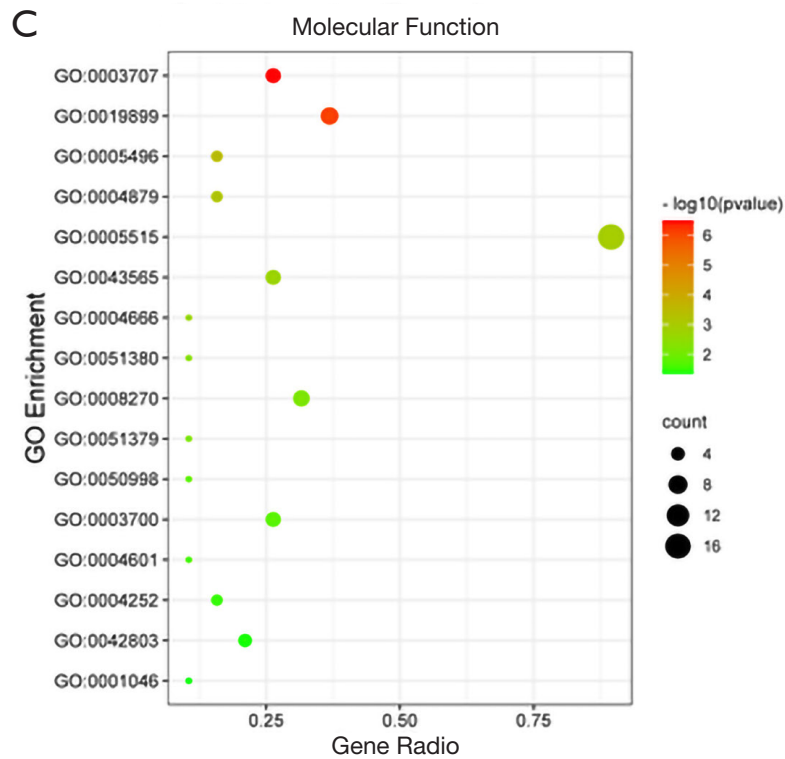

Figure 4 GO enrichment. (A) Biological processes; (B) cell components; (C) molecular functions. GO, Gene Ontology.

Recent years, with the popularization of network pharmacology, it has been used in traditional Chinese medicine research, which could reveal the relationships between disease and active components of traditional Chinese medicine by linking the chemical constituents, targets and pathways to establish a compound-targetpathway network to explore the possible mechanisms in disease treatment. Niu et al. used network pharmacology to predict the active components and targets of Pterocypsela elata for treatment of cerebral ischemia (32). The antiAlzheimer's effects of Bushen Tiansui formula was studied by Zhang et al. using network pharmacology approach (33). In a review, Luo et al. summarized the methodology, application and prospective of network pharmacology technology providing us a new research strategy in the area of Chinese medicine (34).

In this study, 12 identified active components of Caoguo were considered to have potential key roles in the treatment 


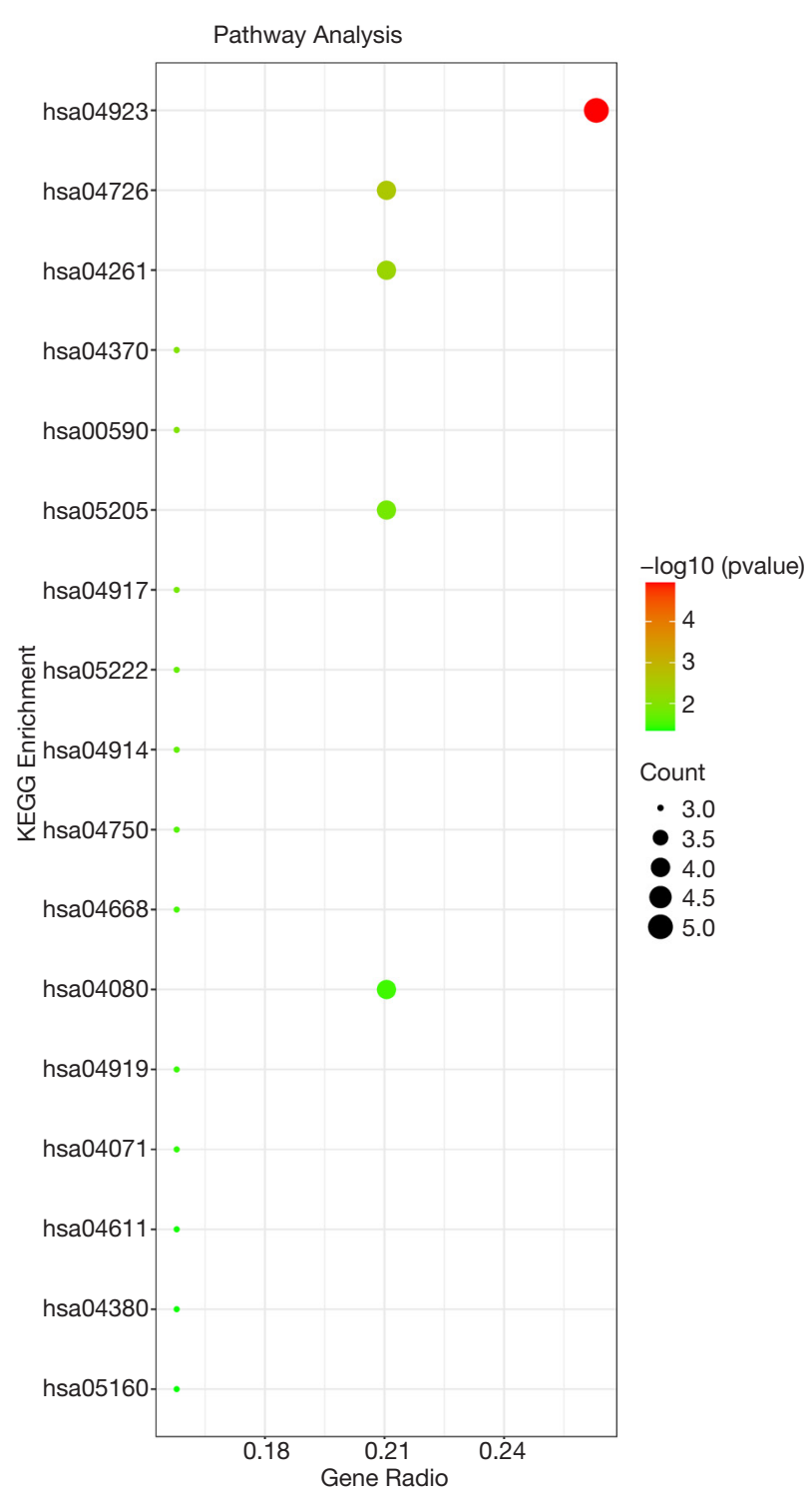

Figure 5 KEGG enrichment analysis of 17 signal pathways.

of indigestion by acting on 19 targets. Based on KEGG enrichment analysis, 17 signal pathways were enriched and analyzed, 2 of which had strong significance and relation. A total of 7 key targets were involved in the top two enriched pathways including regulation of lipolysis in adipocytes (hsa04923) (related to the key target ADRB1, ADRB2, PTGS2, PIK3CG, PTGS1) and serotonergic synapse (hsa04726) (related to the key target HTR2A, PTGS2, SLC6A4, PTGS1).

In the pathway of regulation of lipolysis in adipocytes, Caoguo plays a pharmacological role by promoting the effect of epinephrine and norepinephrine on lipid metabolism and inhibiting the inhibitory effect of insulin and prostaglandin on lipid metabolism. Adrenoceptor beta 1 (ADRB1) and adrenoceptor beta $2(A D R B 2)$ are responsible to activate the regulation of lipolysis in adipocytes. The assembly of $G$ proteins produces a large number of second messengers cAMP which are dispersed into the cells and then activate PKA which enable lipase activation to participate in lipid metabolism and transfer triglycerides into glycerol and fatty acids to the liver. The protein PIK3CG is responsible for the PI3K-Akt insulin signal pathway. Activation of PI3K/Akt/mTOR pathways may be involved in pathogenesis of the gastrointestinal tract (35). The PI3K/Akt signaling pathways is involved in soluble uric acid and the gut excretion in human intestinal cells (36). The proteins PTGS1 and PTGS2 are responsible for arachidonic acid metabolism, which then affects the release of PGE2, causing the direct activation of longitudinal smooth muscle contraction of the colon in rats (37).

In the regulation of serotonergic synapse pathway, Caoguo plays a pharmacological role by inhibiting 5-HT reuptake and promoting the combination of $5-\mathrm{HT}$ to 5 -hydroxytryptamine receptor. Solute carrier family 6 member 4 (SLC6A4) is responsible for the reuptake process by SERT. Up-regulation of SERT levels in the midbrain and thalamus may relate to pathogenesis of the gut (38). SERT reuptakes excessive 5-HT and participates in the regulation of gastrointestinal motility, thus intestinal dysregulation may be due to up-regulation of SERT expression, leading to the development of gastrointestinal diseases (39). Additionally, HTR2A is responsible for the activation of the 5 -HT receptor $2 \mathrm{~A}$ which leads to release of calcium ion and play an important role in controlling gastric emptying (40).

\section{Conclusions}

In this article, a systematic study of the essential volatile chemical components in Caoguo extract and in rats plasma were conducted by application of ASE technique and GC-MS method, which played an important role in the development, modernization, and quality control of Caoguo formulations. Network pharmacology was also introduced to reveal the possible mechanism of Caoguo in treatment of indigestion. This study provided a new strategy using ASE combined with GC-MS for Caoguo extraction and analysis, while enriched our knowledge about its volatile components and the therapeutic material basis. In next work, the prediction signaling pathways need be confirmed 


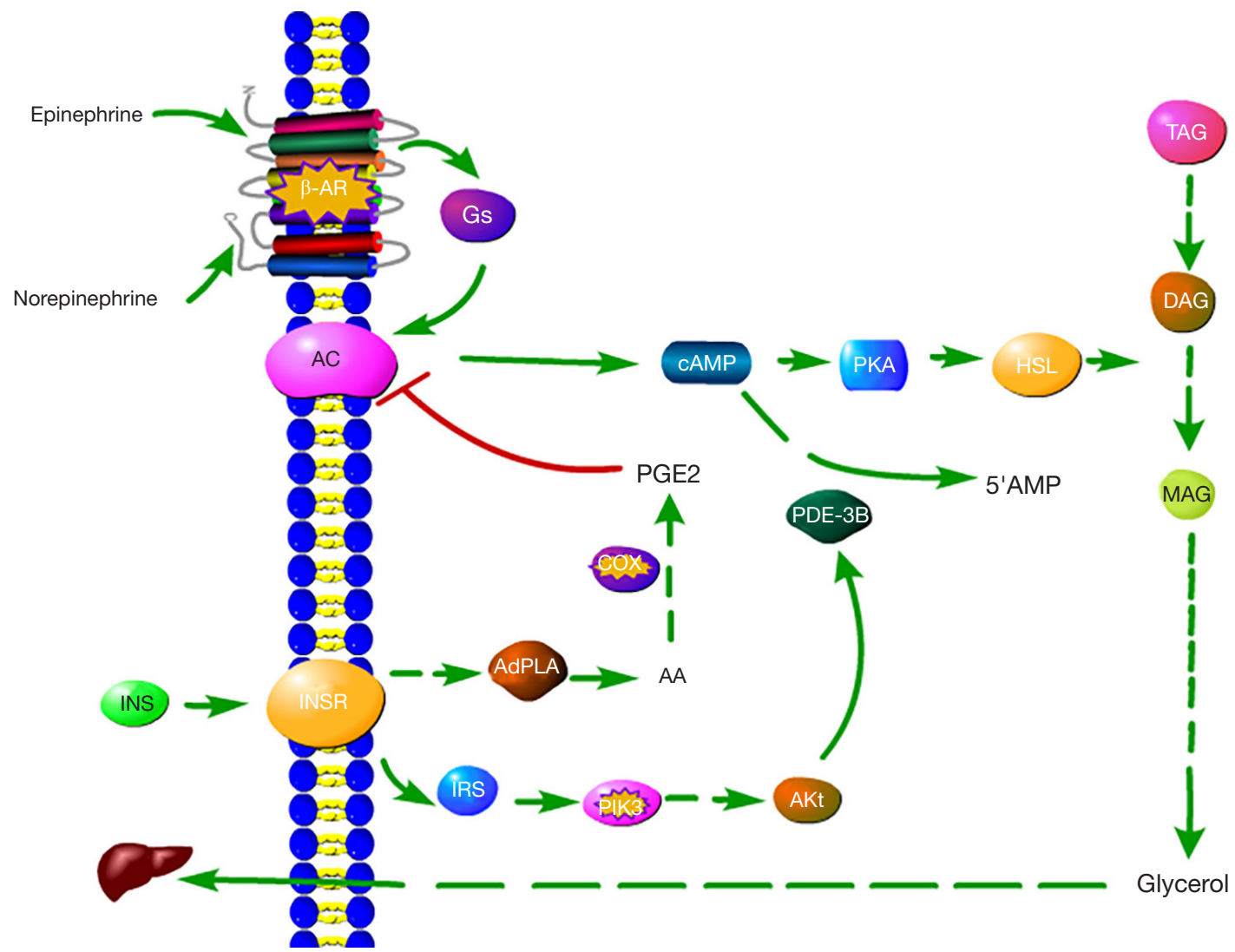

Figure 6 Regulation of lipolysis in adipocytes signal pathway.

A

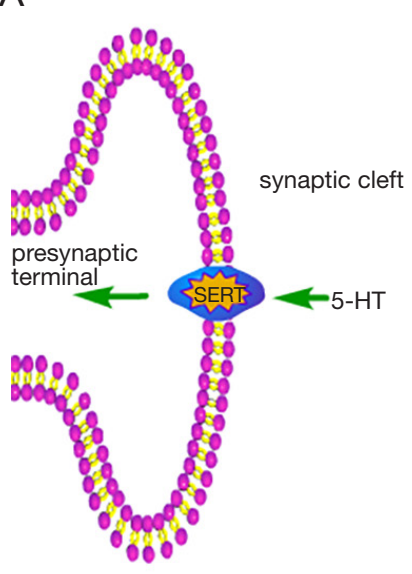

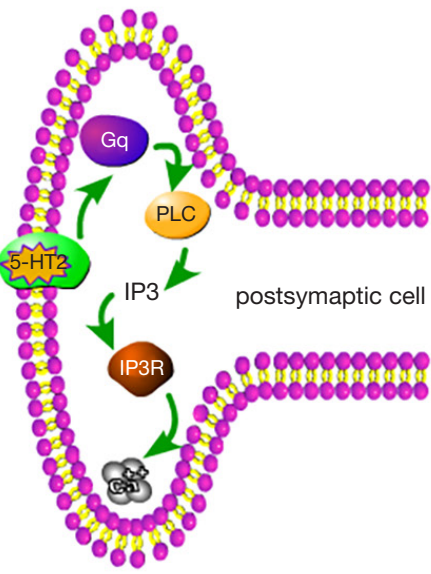

B

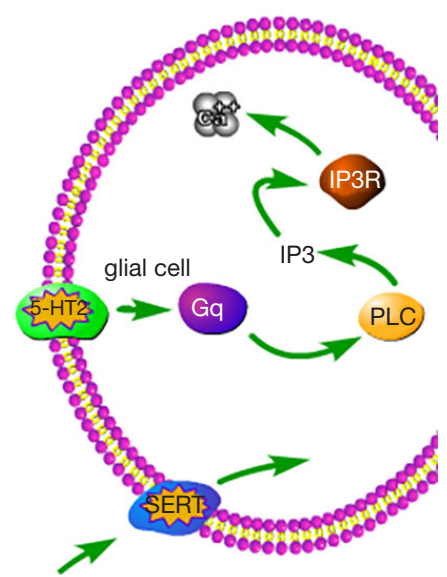

Figure 7 Serotonergic synapse signal pathway. 


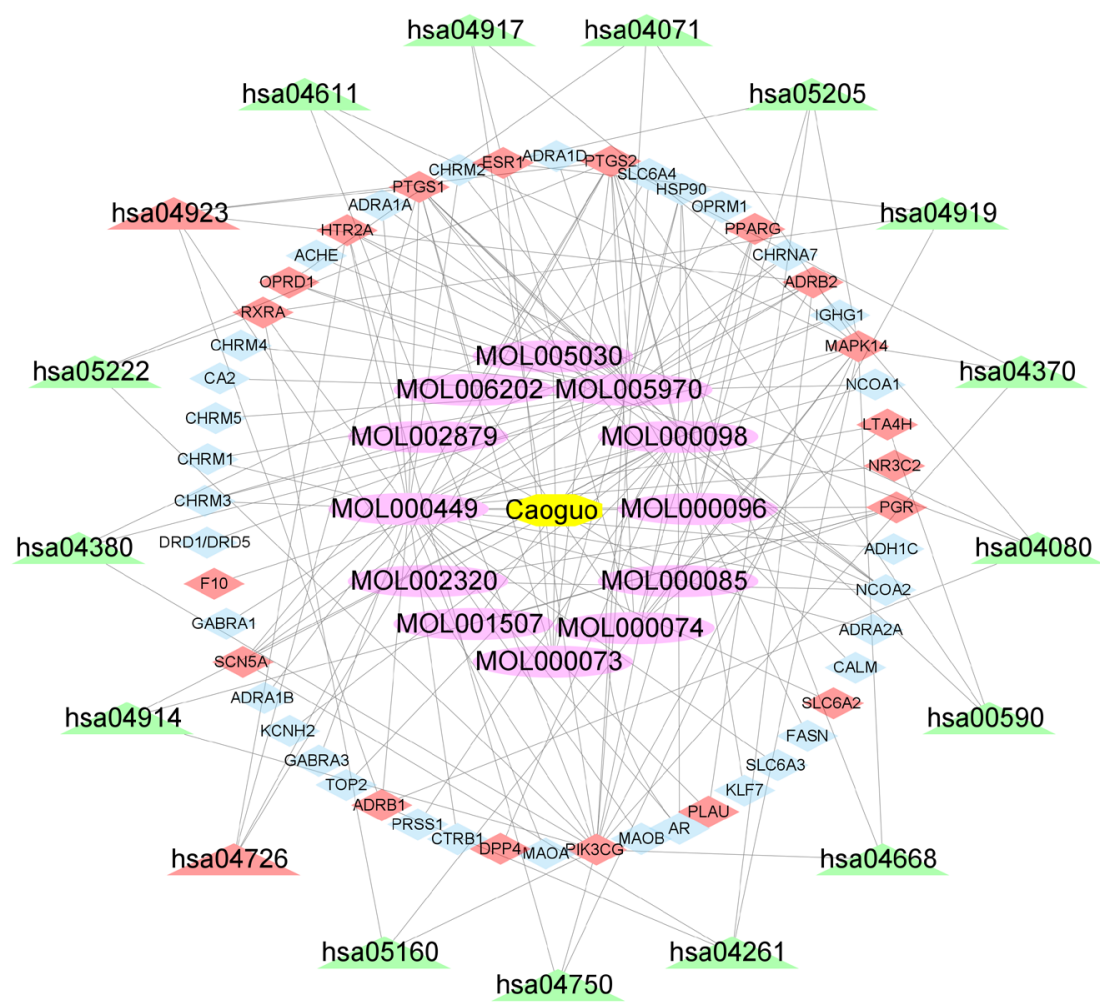

Figure 8 The component-target-pathway network (the yellow node represents the herbal medicine; the 12 purple nodes represent the active components in Caoguo; the 52 rhombuses represent the target genes of the active components in Caoguo, in which 19 red nodes represent the intersecting targets; the 17 triangles represent the pathways and two of them marked in red considered as important).

and verified by further study.

\section{Acknowledgments}

Funding: This work was financially supported by Liaoning Province Natural Science Foundation of China (2020-BS106).

\section{Footnote}

Reporting Checklist: The authors have completed the ARRIVE reporting checklist. Available at https://dx.doi. org/10.21037/atm-21-3245

Data Sharing Statement: Available at https://dx.doi. org/10.21037/atm-21-3245

Conflicts of Interest: All authors have completed the ICMJE uniform disclosure form (available at https:// dx.doi.org/10.21037/atm-21-3245). Dr. Chu reports funding support from Liaoning Province Natural Science Foundation of China (2020-BS-106). The other authors have no conflicts of interest to declare.

Ethical Statement: The authors are accountable for all aspects of the work in ensuring that questions related to the accuracy or integrity of any part of the work are appropriately investigated and resolved. Experiments were performed under a project license (No.: SYPUIACUC-C2018-12-26-103) granted by institutional ethics board of Shenyang Pharmaceutical University, in compliance with Shenyang Pharmaceutical University institutional guidelines for the care and use of animals.

Open Access Statement: This is an Open Access article distributed in accordance with the Creative Commons Attribution-NonCommercial-NoDerivs 4.0 International License (CC BY-NC-ND 4.0), which permits the noncommercial replication and distribution of the article with the strict proviso that no changes or edits are made and the 
original work is properly cited (including links to both the formal publication through the relevant DOI and the license). See: https://creativecommons.org/licenses/by-nc-nd/4.0/.

\section{References}

1. Moon SS, Lee JY, Cho SC. Isotsaokoin, an antifungal agent from Amomum tsao-ko. J Nat Prod 2004;67:889-91.

2. Yang X, Küenzi P, Plitzko I, et al. Bicyclononane aldehydes and antiproliferative constituents from Amomum tsao-ko. Planta Med 2009;75:543-6.

3. Zhang TT, Lu CL, Jiang JG. Bioactivity evaluation of ingredients identified from the fruits of Amomum tsaoko Crevost et Lemaire, a Chinese spice. Food Funct 2014;5:1747-54.

4. He XF, Zhang XK, Geng CA, et al. Tsaokopyranols A-M, 2,6-epoxydiarylheptanoids from Amomum tsao-ko and their $\alpha$-glucosidase inhibitory activity. Bioorg Chem 2020;96:103638.

5. He XF, Wang HM, Geng CA, et al. Amomutsaokols A-K, diarylheptanoids from Amomum tsao-ko and their $\alpha$-glucosidase inhibitory activity. Phytochemistry 2020;177:112418.

6. Shin JS, Ryu S, Jang DS, et al. Amomum tsao-ko fruit extract suppresses lipopolysaccharide-induced inducible nitric oxide synthase by inducing heme oxygenase-1 in macrophages and in septic mice. Int J Exp Pathol 2015;96:395-405.

7. Yu L, Shirai N, Suzuki H, et al. The effect of methanol extracts of tsao-ko (Amomum tsao-ko Crevost et Lemaire) on digestive enzyme and antioxidant activity in vitro, and plasma lipids and glucose and liver lipids in mice. J Nutr Sci Vitaminol (Tokyo) 2010;56:171-6.

8. Zhang TT, Lu CL, Jiang JG. Neuroprotective and AntiInflammatory Effects of Diphenylheptanes from the Fruits of Amomum tsaoko, a Chinese Spice. Plant Foods Hum Nutr 2016;71:450-3.

9. Dai KY, Chen MC. Effective study on the cognitive function and quality of life of epileptic patients was improved by intervention of Caoguo Zhimu Decocition and traditional Chinese medicine emotional intervention. Si Chuan Zhong Yi 2018;36:130-3.

10. WANG WJ, BA Yuan M, DING Z. Proved cases of SHAO Zhao-di treating chronic renal failure with Caoguo Zhimu Decoction. CJTCMP 2017;32:3018-20.

11. Xing YC. Mongolian medicine in treating chronic aplastic anemia. J Med \& Pharm Chin Minor 2012;6:12-3.

12. Li T, Chen WX, Tian JJ. Study on reflux extraction of antioxidant compounds from Amomum tsao-ko. Foof Res Dev 2009;30:23-6.

13. Huang YF, Qin LF, Hu QM, et al. Gas chromatogrphymass spectrometry analysis of essential oil from Amomum tsao-ko Crevost rt Lemarie and Amomum Paratsao-ko S.Q.Tong et Y.M.Xia grow in Guangxi. Chin Med J Res Prac 2014;28:22-4.

14. Wan HY, Gu LL, Liu WT, et al. Extraction of volatile oil from tsaoko by supercritical fluid $\mathrm{CO} 2$ extraction and its component analysis. Mod Chem Ind 2015;35:96-100.

15. Ding YX, Xie XM, Cui XM. Study on the chemical components of essential oils from Amomum tsao-ko with different methods. J Henan U. 2009;28:284-7.

16. Yang L, Zhang Z, Li J, et al. Study on the microwave extraction and chemical constituents of the essential oil from Amomum tsao-ko in Jinping, Yunnan province. Zhong Yao Cai 2004;27:821-3.

17. Zheng CQ, Li CE. Accelerated solvent extraction technology in traditional Chiese medicine active components analysis. Chin J Med Gu 2010;12:1820-1.

18. Chen J, Yang B, Li W, et al. Application of accelerated solvent extraction technique for analysis of active components in traditional Chinese medicinal herbs. Se $\mathrm{Pu}$ 2007;25:628-32.

19. Jarrell JT, Gao L, Cohen DS, et al. Network medicine for Alzheimer's disease and traditional Chinese medicine. Molecules 2018;23:1143.

20. Li S, Zhang B. Traditional Chinese medicine network pharmacology: theory, methodology and application. Chin J Nat Med 2013;11:110-20.

21. Zhang R, Zhu X, Bai H, et al. Network Pharmacology Databases for Traditional Chinese Medicine: Review and Assessment. Front Pharmacol 2019;10:123.

22. Wang P, Zhang Q, Wang Y, et al. Evaluation of Soxhlet extraction, accelerated solvent extraction and microwaveassisted extraction for the determination of polychlorinated biphenyls and polybrominated diphenyl ethers in soil and fish samples. Anal Chim Acta 2010;663:43-8.

23. Giergielewicz-Możajska H, Dąbrowski Ł, Namieśnik J. Accelerated Solvent Extraction (ASE) in the Analysis of Environmental Solid Samples-Some Aspects of Theory and Practice. Crit Rev Anal Chem 2001;31:149-65.

24. Herrero M, Martín-Álvarez PJ, Señoráns FJ, et al. Optimization of accelerated solvent extraction of antioxidants from Spirulina platensis microalga. Food Chem 2005;93:417-23.

25. Lin J, Zheng Y, Xu Y, et al. Analysis of essential oil from Amomum tsaoko by extraction of supercritical $\mathrm{CO} 2$ fluid. 
Zhong Yao Cai 2000;23:145-8.

26. Luedemann A, Strassburg K, Erban A, et al. TagFinder for the quantitative analysis of gas chromatography-mass spectrometry (GC-MS)-based metabolite profiling experiments. Bioinformatics 2008;24:732-7.

27. Suau R, Cabezudo B, Rico R, et al. Direct determination of alkaloid contents in Fumaria species by GC-MS. Phytochem Anal 2002;13:363-7.

28. Ruiz-Matute AI, Hernández-Hernández O, RodríguezSánchez S, et al. Derivatization of carbohydrates for GC and GC-MS analyses. J Chromatogr B Analyt Technol Biomed Life Sci 2011;879:1226-40.

29. Balaban M. Identification of the main phenolic compounds in wood of Ceratonia siliqua by GC-MS. Phytochem Anal 2004;15:385-8.

30. McKinlay JB, Shachar-Hill Y, Zeikus JG, et al. Determining Actinobacillus succinogenes metabolic pathways and fluxes by NMR and GC-MS analyses of 13C-labeled metabolic product isotopomers. Metab Eng 2007;9:177-92.

31. Li XN, Cui H, Song YQ, et al. Analysis of volatile fractions of Schisandra chinensis (Turcz.) Baill. using GC-MS and chemometric resolution. Phytochem Anal 2003;14:23-33.

32. Niu B, Zhang H, Li C, et al. Network pharmacology study on the active components of Pterocypsela elata and the mechanism of their effect against cerebral ischemia. Drug Des Devel Ther 2019;13:3009-19.

33. Zhang Z, Yi P, Yang J, et al. Integrated network pharmacology analysis and serum metabolomics to reveal the cognitive improvement effect of Bushen Tiansui

Cite this article as: Shi S, Luo Y, Ma Y, Chu Y, Wang Y, Chen $\mathrm{X}$, Chu Y. Identification of in vitro-in vivo components of Caoguo using accelerated solvent extraction combined with gas chromatography-mass spectrometry integrated with network pharmacology on indigestion. Ann Transl Med 2021;9(15):1247. doi: 10.21037/atm-21-3245 formula on Alzheimer's disease. J Ethnopharmacol 2020;249:112371.

34. Luo TT, Lu Y, Yan SK, et al. Network Pharmacology in Research of Chinese Medicine Formula: Methodology, Application and Prospective. Chin J Integr Med 2020;26:72-80.

35. Long SH, He Y, Chen MH, et al. Activation of PI3K/ Akt/mTOR signaling pathway triggered by PTEN downregulation in the pathogenesis of Crohn's disease. J Dig Dis 2013;14:662-9.

36. Chen $\mathrm{M}, \mathrm{Lu} X, \mathrm{Lu} \mathrm{C}$, et al. Soluble uric acid increases PDZK1 and ABCG2 expression in human intestinal cell lines via the TLR4-NLRP3 inflammasome and PI3K/Akt signaling pathway. Arthritis Res Ther 2018;20:20.

37. Iizuka Y, Kuwahara A, Karaki S. Role of PGE2 in the colonic motility: PGE2 generates and enhances spontaneous contractions of longitudinal smooth muscle in the rat colon. J Physiol Sci 2014;64:85-96.

38. Tominaga K, Tsumoto C, Ataka S, et al. Regional brain disorders of serotonin neurotransmission are associated with functional dyspepsia. Life Sci 2015;137:150-7.

39. Cao H, Liu X, An Y, et al. Dysbiosis contributes to chronic constipation development via regulation of serotonin transporter in the intestine. Sci Rep 2017;7:10322.

40. van Wyk M, Sommers DK, Moncrieff J. Effects of enhancement and antagonism of 5-hydroxytryptamine activity on the influence of metoclopramide on gastric emptying. Digestion 1993;54:40-3.

(English Language Editor: J. Jones) 